\title{
Inflammasome activation markers are independently associated with hypoalphalipoproteinemia in a Mexican-Mestizo population
}

\begin{abstract}
Background: High-density lipoprotein cholesterol (HDL-C) concentrations are determined by environmental and metabolic factors, but systemic inflammation markers had been less studied.

Aim: To evaluate the independent association of systemic inflammation markers to HDL-C concentration, considering the relative contribution of envioromental, and metabolic factors, in a well-characterized Mexican-Mestizo population.
\end{abstract}

Methods: We used logistic regression and linear regression analysis to assess the effect of inflammatory (high sensitivity C-reactive protein (hs-CRP), adiponectin, tumor necrosis factor alpha, interleukins 6, 10,15, and 1 $\beta$ ), environmental (diet and physical activity) and metabolic factors (triglyceride (TG) levels, insulin resistance, abdominal visceral fat) on HDL-C concentrations, in 907 adults (46.5\% female, aged $52 \pm 9$ years), without diabetes, TG $\leq 600 \mathrm{mg} / \mathrm{dL}$, and hs-CRP $\leq$ $3 \mathrm{mg} / \mathrm{L}$.

Results: We found hypoalphalipoproteinemia (HA: HDL-C $\leq 50 \mathrm{mg} / \mathrm{dL}$ in women and $\leq 40 \mathrm{mg} /$ $\mathrm{dL}$ in men) in $44.8 \%$ of women and $48.8 \%$ of men. Carbohydrate intake (standardized coefficient $\beta:-0.109$ and -0.142$)$, TG $(-0.280$ and -0.418$)$, and interleukin- $1 \beta(-0.156$ and -0.159$)$ were inversely and independently associated to HDL-C levels, whereas adiponectin had a positive effect on the lipoprotein concentrations ( 0.196 and 0.169$)$ for women and men, respectively $(p<0.05$ for all). Conjointly, these variables explained $33 \%$ of the variance in $\mathrm{HDL}-\mathrm{C}$ levels.

Conclusion: The study confirms the strong association of TG and carbohydrate intake with HDL-C levels. In addition, the results highlight the relevance of inflammatory processes in HA, which is one of the most prevalent cardiovascular risk factors in the Mexican population.

Keywords: High density lipoprotein cholesterol " Inflammation " Insulin resistance " Diet; Exercise - Adipose tissue - Cardiovascular risk

Submitted Date: 29 June 2018; Accepted Date: 18 July 2018; Published Date: 20 July 2018

\section{Background}

Clinical and epidemiological studies have established that low high-density lipoprotein cholesterol (HDL-C) levels or hypoalphalipoproteinemia (HA) is a cardiovascular risk factor [1]. HDL-C concentrations are influenced by several modifiable and non-modifiable metabolic or environmental factors that include diet and regular aerobic exercise [2-4].
Hypoalphalipoproteinemia (HDL-C $<40 \mathrm{mg}$ / $\mathrm{dL}$ ) is a frequent dyslipidemia in the Mexican population and its prevalence $(64.7 \%)$ is among the highest reported worldwide [5,6]. A study in an urban population suggested that this high prevalence could be related to the coexistence of hypertriglyceridemia (HTG), insulin resistance (IR), overweight, and smoking [7]. On the other hand, it has been proposed that, compared to body weight
Aida Medina-Urrutia*, Carlos Posadas-Romero, Esteban JorgeGalarza, Ángel R. López-Uribe, del Carmen González-Salazara and Juan G. Juárez-Rojas Departamento de Endocrinología, Instituto Nacional de Cardiología Ignacio Chávez. Juan Badiano 1, Col. Sección XVI, C.P. 14080, Tlalpan, México D.F., México

*Author for correspondence:

E-mail: gaboy2k@gmail.com 
excess, abdominal visceral fat (AVF) could have a stronger association with adverse effects of obesity, including HA [8]. A modulating reciprocal link between HDL and inflammation has been described [9-13], suggesting that several inflammatory could be associated with HDL-C plasma levels. However, to our knowledge, no study has analyzed the relative contribution of systemic inflammation markers to HDL-C in multivariate models, considering enviromental and metabolic factors. Thus, the aim of the present study was to analyze the effect of inflammation markers (high sensitivity C-reactive protein (hs-CRP), adiponectin, tumor necrosis factor alpha (TNF-alpha), and interleukins (IL) $6,10,15$ and $1 \beta$ ), as well as diet, physical activity, smoking, alcohol consumption, HTG, IR, and AVF on HDL-C concentrations and HA prevalence in a wellcharacterized sample of Mexican-Mestizo population.

\section{Materials and Methods}

The Genetics of Atherosclerotic Disease study (GEA, for its Spanish initials) was designed at the National Institute of Cardiology Ignacio Chávez, Mexico City, to assess the genetic bases of coronary artery disease $(\mathrm{CAD})$ and the association of traditional and emerging risk factors with atherosclerosis in the adult Mexican population. The GEA study includes a convenience sample of 1200 patients with premature CAD and a control group of 1500 individuals aged 30-75 years without personal or familial history of CAD, residing in Mexico City. The control group includes subjects who attend the blood bank at our institution and are not relatives of patients, as well as subjects invited through written materials. The Bioethics Committee of the National Institute of Cardiology Ignacio Chávez approved this study in accordance with the principles of the Declaration of Helsinki. Participating subjects signed an informed consent.

All participants answered standardized questionnaires providing information on demographics, familial and personal background history on cardiovascular risk factors, dietary habits, and physical activity, as well as alcohol, tobacco and medication use. For the aims of the present study, we selected subjects of the GEA study control group with TG $\leq 600 \mathrm{mg} / \mathrm{dL}$, no history of diabetes mellitus (DM: defined as fasting plasma glucose $\geq 126 \mathrm{mg} / \mathrm{dL}$, prior medical diagnosis, or antidiabetic treatment use), and no signs of low-grade systemic inflammation (hs-CRP $\leq 3 \mathrm{mg} / \mathrm{L}$ ).

\section{Anthropometric measures and blood pressure}

Weight and height were recorded using a calibrated scale and wall stadiometer. The body mass index (BMI) was calculated as weight $(\mathrm{kg}) /$ height $\left(\mathrm{m}^{2}\right)$. Blood pressure was recorded in triplicate using a Welch Allyn digital sphygmomanometer, after at least five minutes of rest in a sitting position. The average of the last two recordings was used for analysis.

\section{Diet and physical activity}

The subject's habitual dietary intake was assessed using a food frequency survey [14]. The questionnaire included a list of 116 food items and specifications on portion sizes. Fat, protein, and carbohydrate intake was estimated using the previously validated program "System evaluation of nutritional habits and food intake" (SNUT) [15]. Physical activity was assessed using a questionnaire that provides information on frequency, duration and intensity of physical activity at work, during sport at leisure time, and during leisure time excluding sport [16]. The sum of activity during all three periods was recorded as total physical activity

\section{Laboratory tests}

After 10-h fasting and $20 \mathrm{~min}$ in sitting position, venous blood was collected in assay tubes without anticoagulant and in tubes with K2-EDTA $(1.8 \mathrm{mg} /$ $\mathrm{mL}$ ). Glucose, total cholesterol, triglyceride, and HDL-C levels were determined using direct standard enzymatic colorimetric (Roche/Hitachi, Germany) assays in a Hitachi 902 auto-analyzer (Hitachi LTD, Tokyo, Japan). Low density lipoprotein cholesterol (LDL-C) was estimated using the De Long formula. The reproducibility and precision of these determinations were assessed by the Center for Disease Control and Prevention Lipids Standardization Program (LSPCDC, Atlanta, GA, USA). Hs-CRP was quantified by immunonephelometry assay in a BN ProSpec automated analyzer (Dade Behring Marburg GmbH, Germany). Adiponectin was determined by ELISA ( $\mathrm{R}$ and $\mathrm{D}$ systems, Minneapolis USA, Quantine Kit). Interleukins (IL-1 $\beta$, IL-6, IL-10, IL-15, and TNFalpha) were quantified using a high sensitivity Bio-Plex system (Bio-Rad Inc, Hercules, CA, USA). Insulin was quantified by radioimmunoassay (Millipore RIA, St Charles, MO, USA) and insulin resistance was estimated using the homeostasis model assessment $($ HOMA-IR $=$ insulin $(\mathrm{UI} / \mathrm{mL}) \times$ glucose $(\mathrm{mmol} / \mathrm{L}) /$ 22.5) [17].

\section{Computed tomography (CT) study}

Abdominal total fat (ATF) and AVF areas were derived from measurements obtained by computed tomography. The abdominal subcutaneous fat (ASF) 
area was estimated as the difference between ATF and AVF, according to the method described by Kvist et al. [18]. Abdominal CT scans were taken at the L4-L5 intervertebral space level, with a 64-channel multidetector tomograph (Somatom Sensation, Siemens, Forchheim, Germany) and interpreted by an expert radiologist.

\section{Definitions}

Percentiles for HOMA-IR, AVF, IL-1 $\beta$, adiponectin, and sport physical activity were established in a subsample of the GEA control group (127 men and 169 women) without DM, and without cardiometabolic risk factors, namely $\mathrm{BMI}<30 \mathrm{~kg} / \mathrm{m}^{2}$, blood pressure $<140 / 90 \mathrm{mmHg}$, fasting glucose $<100 \mathrm{mg} / \mathrm{dL}$, HDL-C $>40 \mathrm{mg} / \mathrm{dL}$ in men and $>50 \mathrm{mg} / \mathrm{dL}$ in women, and triglyceride levels $<150 \mathrm{mg} / \mathrm{dL}$. High HOMA-IR ( $>3.58$ in women and $>3.12$ in men), AVF $\left(>127 \mathrm{~cm}^{2}\right.$ in women and $>152.7 \mathrm{~cm}^{2}$ in men), and IL- $1 \beta(>0.19 \mathrm{pg} /$ $\mathrm{mL}$ in women and $>0.27 \mathrm{pg} / \mathrm{mL}$ in men) were defined as levels $\geq 75$ th percentile (p75). Low adiponectin ( $\leq$ $8.67 \mu \mathrm{g} / \mathrm{mL}$ in women and $\leq 5.30 \mu \mathrm{g} / \mathrm{mL}$ in men) and sport physical activity $(<1.75$ in women and $<2.25$ in men) were defined as levels $\leq 25$ th percentile (p25).

\section{Statistical analysis}

Measurements are presented as mean \pm standard deviation (S.D.), median (interquartile range) or prevalence. Comparisons were made by t, U MannWhitney or Chi-squared test, as appropriate. To assess the independence of associated variables with HA, we used logistic regression analysis. Additionally, to determine the relative contribution of each independent variable, we performed stepwise linear regression analysis including HDL-C as dependent variable, and IL-1 $\beta$, adiponectin, HOMA-IR, triglycerides, abdominal visceral fat, carbohydrate intake, sport physical activity, smoking, and age as independent variables. Variables with skewed distribution were log-transformed. $\mathrm{p}$ values $<0.05$ were considered statistically significant. Analysis was performed using the statistical package SPSS v15.0 (SPSS Chicago, II, USA).

\section{Results}

The present study included 907 subjects (46.5\% female, aged $52 \pm 9$ years). The HA prevalence was $46.9 \%$ (44.8\% in women and $48.8 \%$ in men; $\mathrm{p}=\mathrm{ns}$ ). Compared to subjects without HA, those with HA showed an adverse metabolic profile, characterized by high total and abdominal adiposity, as well as high levels of TG and HOMA-IR (Table 1). Regarding inflammation markers, subjects with HA had higher levels of hs-CRP, IL-15, and IL-1 $\beta$, but significantly lower values of adiponectin (Table 2). After adjusting

Table 1. Clinical characteristics of GEA-study control subjects stratified by HA

\begin{tabular}{|c|c|c|c|c|}
\hline & $\begin{array}{l}\text { Total population } \\
\qquad n=907\end{array}$ & $\begin{array}{c}\text { HA (-) } \\
n=481\end{array}$ & $\begin{array}{l}\text { HA (+) } \\
n=425\end{array}$ & $\mathbf{p}^{*}$ \\
\hline Men (\%) & 53.4 & 51.6 & 55.5 & ns \\
\hline Age (years) & $52.3 \pm 9.3$ & $53.3 \pm 9.3$ & $51.2 \pm 9.2$ & 0.001 \\
\hline $\mathrm{SBP}(\mathrm{mmHg})$ & $115.6 \pm 16.4$ & $115.8 \pm 16.3$ & $115.4 \pm 16.6$ & ns \\
\hline $\mathrm{DBP}(\mathrm{mmHg})$ & $72.0 \pm 9.4$ & $71.8 \pm 9.4$ & $72.1 \pm 9.3$ & ns \\
\hline BMI $\left(\mathrm{kg} / \mathrm{m}^{2}\right)$ & $27.6 \pm 3.8$ & $26.9 \pm 3.9$ & $28.4 \pm 3.6$ & $<0.0001$ \\
\hline Waist (cm) & $92.9 \pm 11.1$ & $90.8 \pm 11.1$ & $95.4 \pm 10.5$ & $<0.0001$ \\
\hline $\operatorname{TAF}\left(\mathrm{cm}^{2}\right)$ & $413(329-502)$ & $393(304-491)$ & $428(359-524)$ & $<0.0001$ \\
\hline $\operatorname{AVF}\left(\mathrm{cm}^{2}\right)$ & 139(101-181) & $122(89-172)$ & $152(120-191)$ & $<0.0001$ \\
\hline $\operatorname{ASF}\left(\mathrm{cm}^{2}\right)$ & $267(199-330)$ & $259(193-326)$ & $275(210-335)$ & $<0.05$ \\
\hline $\mathrm{TC}(\mathrm{mg} / \mathrm{dL})$ & $192.3 \pm 35.0$ & $199.3 \pm 34.0$ & $184.2 \pm 34.5$ & $<0.0001$ \\
\hline LDL-C (mg/dL) & $118.0 \pm 30.3$ & $120.5 \pm 30.5$ & $115.2 \pm 29.9$ & $<0.01$ \\
\hline $\mathrm{HDL}-\mathrm{C}(\mathrm{mg} / \mathrm{dL})$ & $46.9 \pm 13.7$ & $56.2 \pm 11.5$ & $36.4 \pm 6.6$ & $<0.0001$ \\
\hline TG (mg/dL) & 144(106-196) & $122(92-158)$ & $178(131-236)$ & $<0.0001$ \\
\hline Glucose (mg/dL) & $89.5 \pm 8.8$ & $88.8 \pm 8.8$ & $90.2 \pm 8.8$ & $<0.05$ \\
\hline Insulin ( $\mu \mathrm{U} / \mathrm{mL})$ & $16.0(11.5-22.0)$ & $14.1(10.4-20.1)$ & $18.2(13.5-24.6)$ & $<0.0001$ \\
\hline HOMA-IR & $3.4(2.5-5.0)$ & $3.0(2.2-4.4)$ & $3.9(2.9-5.5)$ & $<0.0001$ \\
\hline \multicolumn{5}{|c|}{$\begin{array}{l}\text { GEA: Genetics of Atherosclerotic Disease study, HA: Hypoalphalipoproteinemia (HDL-C } \leq 50 \mathrm{mg} / \mathrm{dL} \text { in women or HDL-C } \leq 40 \mathrm{mg} / \\
\mathrm{dL} \text { in men). Data are expressed as mean } \pm \text { S.D. or median (interquartile range). SBP: systolic blood pressure, DBP: diastolic blood } \\
\text { pressure, BMI: body mass index, TAF: total abdominal fat, AVF: abdominal visceral fat, ASF: abdominal subcutaneous fat, TC: total } \\
\text { cholesterol, LDL-C: low density lipoprotein cholesterol, HDL-C: high-density lipoprotein cholesterol, TG: triglycerides, HOMA-IR: } \\
\text { homeostasis model assessment of insulin resistance. } \\
\text { * t-Student or Mann-Whitney U test according to variable distribution. }\end{array}$} \\
\hline
\end{tabular}




\begin{tabular}{|c|c|c|c|c|}
\hline & $\begin{array}{l}\text { Total population } \\
\qquad \mathbf{n}=907\end{array}$ & $\begin{array}{c}\text { HA (-) } \\
n=481\end{array}$ & $\begin{array}{l}\text { HA (+) } \\
n=425\end{array}$ & p* \\
\hline hs-CRP (mg/L) & $1.0(0.6-1.7)$ & $1.0(0.6-1.7)$ & $1.2(0.8-1.7)$ & 0.001 \\
\hline $\mathrm{TNF} \alpha(\mathrm{pg} / \mathrm{mL})$ & $0.56(0.03-1.80)$ & $0.56(0.04-1.59)$ & $0.56(0.02-2.03)$ & n.s. \\
\hline IL-15 (pg/mL) & $1.51(0.50-2.86)$ & $1.29(0.33-2.39)$ & $1.93(0.76-3.49)$ & $<0.0001$ \\
\hline $\mathrm{IL}-1 \beta(\mathrm{pg} / \mathrm{mL})$ & $0.17(0.09-0.29)$ & $0.14(0.05-0.25)$ & $0.20(0.13-0.33)$ & $<0.0001$ \\
\hline IL-6 (pg/mL) & $0.86(0.40-1.67)$ & $0.81(0.39-1.57)$ & $0.97(0.41-1.87)$ & n.s. \\
\hline IL-10 (pg/mL) & $0.46(0.26-0.98)$ & $0.47(0.29-0.95)$ & $0.45(0.23-1.09)$ & n.s. \\
\hline Adiponectin $(\mu \mathrm{g} / \mathrm{mL})$ & $8.3(5.2-13.17)$ & $10.1(6.4-15.4)$ & $6.5(4.3-10.0)$ & $<0.0001$ \\
\hline
\end{tabular}

Table 3. Diet, physical activity, smoking, and alcohol use in GEA-study control subjects, stratified by HA

\begin{tabular}{|c|c|c|c|c|}
\hline & $\begin{array}{c}\text { Total population } \\
\qquad \mathbf{n}=907\end{array}$ & $\begin{array}{c}\text { HA(-) } \\
n=481\end{array}$ & $\begin{array}{c}H A(+) \\
n=425\end{array}$ & $\mathbf{p}^{*}$ \\
\hline Total kcal & $2325 \pm 699$ & $2299 \pm 704$ & $2347 \pm 689$ & n.s. \\
\hline Protein (\%) & $13.9 \pm 2.3$ & $14.2 \pm 2.4$ & $13.6 \pm 2.2$ & $<0.0001$ \\
\hline $\mathrm{CHO}(\%)$ & $53.8 \pm 6.9$ & $52.6 \pm 6.9$ & $55.1 \pm 6.6$ & $<0.0001$ \\
\hline Fat (\%) & $32.3 \pm 5.9$ & $33.2 \pm 6.1$ & $31.3 \pm 5.6$ & $<0.0001$ \\
\hline Work PA & $2.8 \pm 0.6$ & $2.8 \pm 0.6$ & $2.8 \pm 0.6$ & n.s. \\
\hline Sports PA & $2.4 \pm 0.7$ & $2.5 \pm 0.7$ & $2.3 \pm 0.7$ & $<0.0001$ \\
\hline Leisure PA & $2.7 \pm 0.6$ & $2.8 \pm 0.6$ & $2.7 \pm 0.6$ & $<0.05$ \\
\hline Total PA & $7.9 \pm 1.2$ & $8.1 \pm 1.2$ & $7.8 \pm 1.2$ & 0.001 \\
\hline Smoking (\%) & 23.2 & 21.4 & 25.4 & n.s. \\
\hline Alcohol (\%) & 77.1 & 79.8 & 74.1 & $<0.05$ \\
\hline
\end{tabular}

inflammatory marker values for age, BMI, and HOMA-IR, only mean values (CI95\%) of IL-1 $\beta$ (HA(-): 0.24(0.07-0.11) vs. $\mathrm{HA}(+)$ : 0.52(0.34-0.70), $\mathrm{p}=0.03)$ and adiponectin $(\mathrm{HA}(-): 11.8[11.2-12.5] v s$. $\mathrm{HA}(+)$ : 8.6[7.9-9.3], $\mathrm{p}<0.0001)$ remained statistically significant.

Regarding environmental factors (Table 3), we found that compared to subjects without HA, those with HA had significantly higher intake of carbohydrates, including simple $(21.9 \pm 6.8 \%$ vs. $23.5 \pm 7.0 \%$, $\mathrm{p}<0.0001)$ and complex $(30.8 \pm 7.7 \%$ vs. $31.8 \pm$ $7.1 \%, \mathrm{p}=0.06)$. On the other hand, protein and fat intake was significantly lower in the HA group; lower saturated $(10.0 \pm 2.2 \%$ vs. $9.6 \pm 2.2 \%, \mathrm{p}<0.01)$ and monounsaturated $(14.7 \pm 3.5 \%$ vs. $13.5 \pm 3.0 \%$, p < $0.0001)$ fat intake was noteworthy in this group. Total physical activity at work, sport, and leisure time, as well as alcohol consumption, were lower in the HA group.

When HA subjects were compared by sex, higher prevalences of HTG (72.5\% vs. $55.0 \%$, p < 0.0001$)$, IR (62.4\% vs. $52.4 \%, \mathrm{p}<0.05)$, and $\mathrm{AVF}>\mathrm{p} 75$ (64.9\% vs.
$54.5 \%, \mathrm{p}<0.05)$ were found in men, whereas prevalence of IL- $1 \beta>$ p 75 was higher in women ( $49.2 \%$ vs. $37.7 \%$, $\mathrm{p}<0.05)$.

Gender specific logistic regression analyses were used to assess whether HA was associated with environmental and/or metabolic factors (Figure 1). Hypertriglyceridemia, IL- $1 \beta>\mathrm{p} 75$, adiponectin $<\mathrm{p} 25$, and physical activity during sport $<\mathrm{p} 25$ increased the risk of HA for men and women. Abdominal visceral fat $>$ p75 in women (Figure 1A) and carbohydrate intake $>55 \%$ in men (Figure 1B) were also associated with HA. Linear stepwise regression analysis was used to estimate the magnitude of each variable's effect (Table 4). This analysis showed that TG, inflammation markers, and carbohydrate intake were the major determinants of HDL-C levels for men and women, whereas age and abdominal visceral fat were significantly associated to HDL-C only in women. Of note, Table 4 shows that compared to women, TG had a higher impact on HA in men, whereas inflammation was associated stronger with this dyslipidemia in women. Conjointly, these 


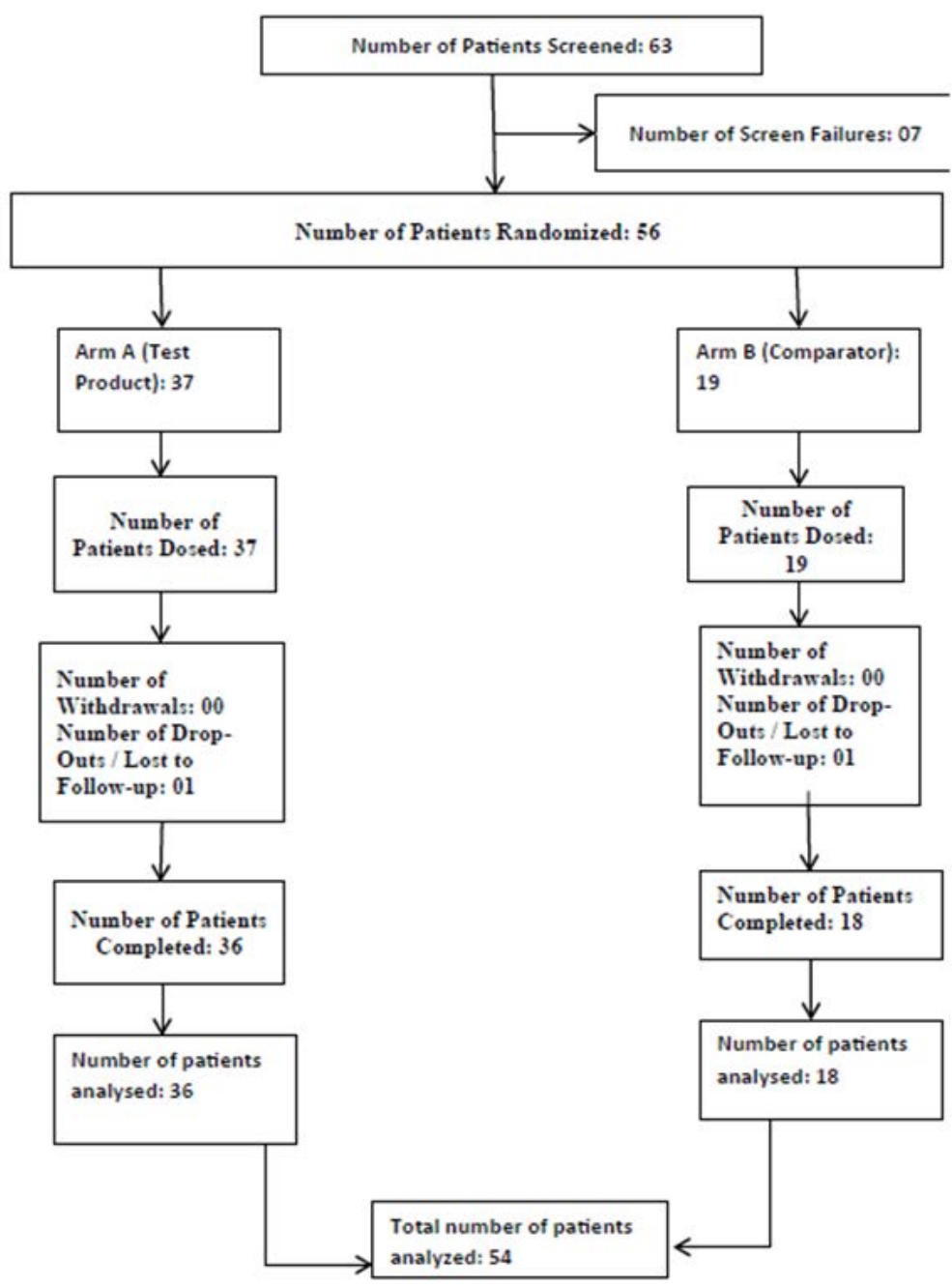

Figure 1: Multivariate analysis of variables associated with $\mathrm{HA}$ : Hypoalphalipoproteinemia (HDL-C $\leq 50 \mathrm{mg} / \mathrm{dL}$ in women or HDL-C $\leq$ $40 \mathrm{mg} / \mathrm{dL}$ in men). HTG: fasting triglycerides $\geq 150 \mathrm{mg} / \mathrm{dL}, \mathrm{CHO}$ 's: Dietary carbohydrates. Percentile 75 (p75) values of IL-1 $\beta$, HOMAIR and AVF, correspond to: $0.19 \mathrm{pg} / \mathrm{mL}, 0.27 \mathrm{pg} / \mathrm{mL}, 3.66,3.38$ and $122 \mathrm{~cm}^{2}, 151.5 \mathrm{~cm}^{2}$, for women and men, respectively. Percentile 25 (p25) of adiponectin (ADIPO) and sport physical activity [PA], correspond to $8.0 \mu \mathrm{g} / \mathrm{mL}, 5.3 \mu \mathrm{g} / \mathrm{mL}$ and $1.75,2.25$, for women and men, respectively.

Table 4. Linear regression analysis of variables associated to HDL-C by gender

\begin{tabular}{|c|c|c|c|c|}
\hline & $\beta$ & standardized $\beta$ & partial $\mathbf{R}^{2}$ & $\mathbf{P}$ \\
\hline \multicolumn{5}{|l|}{ Women } \\
\hline Ln TG (mg/dl) & -10.1 & -0.280 & 0.188 & $<0.0001$ \\
\hline Ln Adipo $(\mu \mathrm{g} / \mathrm{ml})$ & 4.4 & 0.196 & 0.064 & $<0.0001$ \\
\hline Ln IL-1 $\beta(p g / m l)$ & -1.7 & -0.156 & 0.027 & 0.001 \\
\hline Age (years) & 0.3 & 0.206 & 0.022 & $<0.0001$ \\
\hline $\operatorname{Ln}$ AVF $\left(\mathrm{cm}^{2}\right)$ & -4.8 & -0.138 & 0.015 & $<0.01$ \\
\hline Carbohydrates (\%) & -0.23 & -0.109 & 0.011 & $<0.05$ \\
\hline \multicolumn{5}{|l|}{ Men } \\
\hline Ln TG (mg/dl) & -9.2 & -0.418 & 0.267 & $<0.0001$ \\
\hline Ln Adipo $(\mu \mathrm{g} / \mathrm{ml})$ & 2.8 & 0.169 & 0.031 & $<0.0001$ \\
\hline $\operatorname{Ln} \mathrm{IL}-1 \beta(\mathrm{pg} / \mathrm{ml})$ & -1.5 & -0.159 & 0.018 & $<0.0001$ \\
\hline Carbohydrates (\%) & -0.22 & -0.142 & 0.019 & 0.001 \\
\hline
\end{tabular}


variables explained $33 \%$ of the total variance in HDL-C levels for both genders.

\section{Discussion}

The present study analyzed the impact of metabolic and environmental factors on HDL-C concentrations in a Mexican-Mestizo population without clinical evidence of diabetes mellitus or cardiovascular disease. The results showed that TG, IL-1 $\beta$, and carbohydrate intake were independently and inversely related to HDL-C levels, whereas adiponectin had a direct effect on HDL-C in men and women. These variables explained $33 \%$ of the total HDL-C variance. To our knowledge, this is the first study that considers biochemical variables, body composition, diet, and physical activity, in a multivariate model, to evaluate their individual and relative contribution to HDL-C levels. The main contribution of the present study is documenting that, independently of adiposity and insulin resistance, systemic inflammation markers are associated with HDL-C. Additionally, results broaden current information by analyzing the specific effect of abdominal visceral fat on HDL-C.

Two epidemiological studies, performed in representative populations of Mexican adults in whom fasting plasmatic lipid and lipoprotein levels were quantified, report mean concentrations of HDL-C of $38 \mathrm{mg} / \mathrm{dL}$ [6,7], which are lower than those reported in the present study $(46.9 \pm 13 \mathrm{mg} / \mathrm{dL})$. These results may be explained, at least partially, by the selection criteria of the studied populations. Compared to our sample, which included adults without family or personal history of cardiovascular disease and no evidence of diabetes or inflammatory processes (hs-CRP $\leq 3 \mathrm{mg} / \mathrm{dL}$ ), the previous reports included open populations in which the presence of the above mentioned cardiovascular risk factors could account for lower HDL-C concentrations. The cut-off points on HDL-C levels to define HA have not been determined consistently or gender specifically. Considering a cutoff point of $35 \mathrm{mg} / \mathrm{dL}$, Aguilar-Salinas et al. [7] found HA in $48.4 \%$ of the urban population studied $58.8 \%$ in men and $40.8 \%$ in women). Barquera et al. [6] used a cut-off point of $40 \mathrm{mg} / \mathrm{dL}$ and reported $\mathrm{HA}$ in $64.7 \%$ of men and $61.4 \%$ in women. The present study found that age adjusted HDL-C mean concentration shows significant differences $(\mathrm{p}<0.0001)$ between men $(42.4$ $\pm 0.6 \mathrm{mg} / \mathrm{dL})$ and women $(52.4 \pm 0.6 \mathrm{mg} / \mathrm{dL})$; which suggests that a single cut-off point use for both genders may lead to an incorrect estimation of the prevalence of HA. Accordingly, we used the proposed American
Diabetes Association cut-off point $(40 \mathrm{mg} / \mathrm{dL}$ in men and $50 \mathrm{mg} / \mathrm{dL}$ in women) [19]. We found low HDL-C levels in $48.8 \%$ and $44.8 \%$ of men and women, respectively. These results confirm a high prevalence of low HDL-C levels in the adult Mexican population, even in subjects without important associated cardiovascular risk factors.

Regarding the modifiable factors associated to HA, it has been suggested that high simple carbohydrate and limited fat intake, scarce physical activity, and smoking contribute to the low levels of HDL-C found in our population [6,7]. However, these previous studies did not analyze the effect of physical activity, diet and VAF on HDL-C concentrations. The present study shows that unlike smoking, carbohydrate and saturated fat intake and physical activity are associated to HDL-C levels in univariate models (Table 2). Additionally, logistic regression analysis showed that scarce physical activity $(<\mathrm{p} 25)$ in men and women, and high total carbohydrate intake ( $>55 \%)$ in men accounted for up to twofold increases in the risk for HA (Figure 1). On the other hand, the multivariate linear regression model showed that total carbohydrate intake is inversely and independently associated to HDL-C levels (Table 3), suggesting the important participation of this dietary component in the modulation of HDL-C levels in our population. It has been suggested that this association is related to the effect of carbohydrates on the secretion of triglyceride-rich lipoproteins (very low-density lipoproteins VLDL) [7].

Aguilar-Salinas et al. report that hypertriglyceridemia and insulin resistance are found together with low HDL-C levels in $60 \%$ of cases [7]. Results of the present study confirm this finding and broaden the information by showing that, independently of other metabolic and environmental factors, TG levels were the strongest variable associated to HDL-C levels, explaining $19 \%$ and $27 \%$ of its variance in women and men, respectively. The inverse relationship of TG and HDL-C levels has been extensively described [20] and it has been posited that IR plays an important role in this association. Insulin resistance, mainly associated with adiposity excess [20,21], is associated with hepatic overproduction of VLDL as well as with an increase in cholesteryl ester transfer protein and hepatic lipase (HL) activity. This promotes higher HDL renal clearance and, hence, decreases circulating HDL-C [21]. In contrast to the above-mentioned suggestion, results of the present study indicate that IR does not seem to participate directly in the HDL-C regulation of the studied population. Abdominal visceral fat was 
inversely and independently associated with HDL-C only in women (Table 3 and Figure 1). Furthermore, analysis of TG level determinants (the strongest factor association with $\mathrm{HDL}$ ) revealed that AVF, inflammation markers (adiponectin and IL-1 $\beta$ ), and carbohydrate intake, but not HOMA-IR, explained $28 \%$ of the TG variance (data not shown). These results suggest direct participation of dietary composition, excess adiposity and inflammation on the HDL-C regulation in Mexican population.

In line with our results, other reports have shown that HDL-C levels are positively associated with adiponectin [9,22-24] beyond adiposity [23,25] and insulin resistance $[24,26]$. Data supporting these observations indicate that there is a significant inverse association between adiponectin levels and HL activity, independent of insulin and BMI in subjects with or without type 2 DM [27]. Additionally, another study showed that adiponectin increases lipoprotein lipase activity (LPL) [28], an enzyme that participates in the chylomicrons and VLDL hydrolysis, promoting TG clearance and lower TG plasma concentrations. The adiponectin effect on HL and LPL may decreases renal clearance of HDL. On the other hand, studies in cellular and animal models have shown that adiponectin can activate the peroxisome proliferator-activated receptor alpha (PPAR-alpha), leading to increase in apolipoprotein A-I hepatic production. In macrophages and hepatocytes, adiponectin activates the liver $\mathrm{X}$ nuclear receptor and stimulates expression of the ATP-binding cassette transporter (ABCA1) [29], which favor cholesterol efflux and HDL synthesis [30]. Collectively considered, these findings suggest that adiponectin increases the synthesis and decreases HDL clearance, which suppoarts the findings reported in epidemiological studies [6,7], as well as in the present study.

Besides promoting cholesterol efflux, HDL has antiinflammatory and antioxidant properties, exerts antiplatelet aggregation function, and favors nitric oxide production in the vascular endothelium [10]. In regards to anti-inflammatory properties, it has been reported that $\mathrm{HA}$ is frequently observed in autoimmune diseases [10]. Interleukin $1 \beta$, one of the end products of the NLRP3 inflammasome complex (NOD-like receptor, pyrin domain containing 3) [31], is mainly produced by macrophages, but also by endothelial and smooth muscle cells, in response to proinflammatory signals that activates inflammasome [12]. Recently, experimental findings have shown that HDL can inhibit the synthesis of some components of NLRP3 inflammasome and thus reduce IL-1 $\beta$ production; although the exact mechanisms of this process remains unclear [11,12], our findings support for the first time the independent and inverse association of IL- $1 \beta$ with HDL-C in an epidemiological study.

This study has several strengths. First, the distribution of body fat was measured by computed tomography, which is a specific and reliable method to quantify abdominal visceral fat (AVF). Thus, it was possible to assess the influence of AVF on HDL-C, beyond clinical anthropometry. Second, multivariate analysis included physical activity, caloric intake, body composition, and inflammation markers, which are known to affect HDL-C levels and have not been analyzed together in previous studies. Among the study limitations, it should be mentioned that because this is a cross-sectional design we could not infer causality from the results. Moreover, it was not possible to measure multimeric forms of adiponectin, which are critical determinants of IR. Nevertheless, because circulating levels of multimeric adiponectin have been reported to show a strong correlation with total adiponectin circulating levels $(\mathrm{r}=0.95, \mathrm{p}<0.0001) \quad$ [32], the associations observed here would be expected to be similar. Finally, although insulin resistance was estimated using the homeostasis model assessment, which is a surrogate marker of IR, it is a better suited for large population studies. Moreover, this algoritm does correlate with results of the euglycemic clamp technique, the gold standard for assessing IR [33].

\section{Conclusion}

Results of the present study show that in addition to carbohydrate intake and TG, inflammation markers such as IL-1 $\beta$ and adiponectin, were independently associated to HDL-C levels in Mexican-Mestizo subjects. Although causality in these findings must be confirmed by prospective studies, our results are significant since they draw attention, for the first time, to the importance of inflammatory processes in HA, which is one of the most prevalent cardiovascular risk factor in Mexican population.

\section{Conflicts of Interest}

The authors declare that they have no conflicts of interest in the research.

\section{Financing}

The "Genetics of Atherosclerosis Disease" (GEA) study is supported by the National Council of Science and Technology (CONACYT) (Project number: SALUD-2014-1-233727). 


\section{Acknowledgment}

The authors of the present paper thank the personnel of the Endocrinology and Tomography and Imaging Departments at the National Institute of Cardiology "Ignacio Chavez" as well as the study's participants.

Executive summary

Background: High-density lipoprotein cholesterol (HDL-C) concentrations are determined by environmental and metabolic factors, but systemic inflammation markers had been less studied.

Aim: To evaluate the independent association of systemic inflammation markers to HDL-C concentration, considering the relative contribution of envioromental, and metabolic factors, in a well-characterized Mexican-Mestizo population.

Methods: We used logistic regression and linear regression analysis to assess the effect of inflammatory (high sensitivity C-reactive protein (hs-CRP), adiponectin, tumor necrosis factor alpha, interleukins $6,10,15$, and $1 \beta$ ), environmental (diet and physical activity) and metabolic factors (triglyceride (TG) levels, insulin resistance, abdominal visceral fat) on HDL-C concentrations, in 907 adults (46.5\% female, aged $52 \pm 9$ years), without diabetes, $\mathrm{TG} \leq 600 \mathrm{mg} / \mathrm{dL}$, and hs-CRP $\leq 3 \mathrm{mg} / \mathrm{L}$.

Results: We found hypoalphalipoproteinemia (HA: HDL-C $\leq 50 \mathrm{mg} / \mathrm{dL}$ in women and $\leq 40 \mathrm{mg} / \mathrm{dL}$ in men) in $44.8 \%$ of women and $48.8 \%$ of men. Carbohydrate intake (standardized coefficient $\beta$ : -0.109 and -0.142$)$, TG (-0.280 and -0.418$)$, and interleukin- $1 \beta$ $(-0.156$ and -0.159$)$ were inversely and independently associated to $\mathrm{HDL}-\mathrm{C}$ levels, whereas adiponectin had a positive effect on the lipoprotein concentrations ( 0.196 and 0.169$)$ for women and men, respectively ( $p<0.05$ for all). Conjointly, these variables explained $33 \%$ of the variance in $\mathrm{HDL}-\mathrm{C}$ levels.

Conclusion: The study confirms the strong association of TG and carbohydrate intake with HDL-C levels. In addition, the results highlight the relevance of inflammatory processes in $\mathrm{HA}$, which is one of the most prevalent cardiovascular risk factors in the Mexican population.

\section{References}

1. Rosenson RS. The High-Density Lipoprotein Puzzle: Why Classic Epidemiology, Genetic Epidemiology, and Clinical Trials Conflict? Arterioscler Thromb Vasc Biol 36:777-782 (2016).

2. Li N, Fu J, Koonen DP, et al. Are hypertriglyceridemia and low HDL causal factors in the development of insulin resistance? Atherosclerosis 233:130-138 (2014).

3. O'Keefe JH, Bhatti SK, Bajwa A, et al. Alcohol and cardiovascular health: the dose makes the poison...or the remedy. Mayo Clin Proc 89:382-393 (2014)

4. Zhang B, Kawachi E, Miura S, et al. Therapeutic approaches to the regulation of metabolism of high-density lipoprotein. Novel HDL-directed pharmacological intervention and exercise. Circ J 77: 2651-2663 (2013)

5. Aguilar-Salinas CA, Canizales-Quinteros S, Rojas-Martínez $\mathrm{R}$, et al. Hypoalphalipoproteinemia in populations of Native American ancestry: an opportunity to assess the interaction of genes and the environment. Curr Opin Lipidol 20:92-97 (2009).

6. Barquera S, Flores M, Olaiz-Fernández G, et al. Dyslipidemias and obesity in Mexico. Salud Pública de México 49:s338-s347 (2007).

7. Aguilar-Salinas CA, Olaiz G, Valles V, et al. High prevalence of low HDL cholesterol concentrations and mixed hyperlipidemia in a Mexican nationwide survey. J Lipid Res 42:1298-1307 (2001).

8. Bays H. Central obesity as a clinical marker of adiposopathy; increased visceral adiposity as a surrogate marker for global fat dysfunction. Curr Opin Endocrinol Diabetes Obes 21:345-351 (2014).

9. Christou GA, Kiortsis DN. Adiponectin and lipoprotein metabolism. Obes Rev 14:939-949 (2013).
10. Yu BL, Wang SH, Peng DQ, et al. HDL and immunomodulation: an emerging role of HDL against atherosclerosis. Immunol Cell Biol 88:285-290 (2010).

11. Spillmann F, De Geest B, Muthuramu I, et al. Apolipoprotein A-I gene transfer exerts immunomodulatory effects and reduces vascular inflammation and fibrosis in ob/ob mice. J Inflamm 13:25 (2016).

12. Thacker SG, Zarzour A, Chen Y, et al. High-density lipoprotein reduces inflammation from cholesterol crystals by inhibiting inflammasome activation. Immunology 149:306-319 (2016).

13. Van Linthout S, Foryst-Ludwig A, Spillmann F, et al. Impact of $\mathrm{HDL}$ on adipose tissue metabolism and adiponectin expression. Atherosclerosis 210:438-444 (2010).

14. Hernández-Avila M, Romieu I, Parra S, et al. Validity and reproducibility of a food frequency questionnaire to assess dietary intake of women living in Mexico City. Salud Pública Mex 40:133-140 (1998).

15. Hernández-Ávila $M$, Resoles $M$, Parra $S$, et al. Sistema de evaluación de hábitos nutricionales y consumo de nutrimentos (SNUT), INSP, Cuernavaca, México. Nutr Hosp 33:663-670 (2016).

16. Baecke JA, Burema J, Frijters JE. A short questionnaire for the measurement of habitual physical activity in epidemiological studies. Am J Clin Nutr 36:936-942 (1982).

17. Matthews DR, Hosker JP, Rudenski AS, et al. Homeostasis model assessment insulin resistance and beta-cell function from fasting plasma glucose and insulin concentration in man. Diabetologia 28:412-419 (1985).

18. Kvist H, Chowdhury B, Grangard U, et al. Total and visceral adipose-tissue volumes derived from measurement with computed tomography in adult men and women: predicted 
equations. Am J Clin Nutr 48:1351-1361 (1988).

19. Alberti KG, Eckel RH, Grundy SM, et al. International Diabetes Federation Task Force on Epidemiology and Prevention; National Heart, Lung, and Blood Institute; American Heart Association; World Heart Federation; International Atherosclerosis Society; International Association for the Study of Obesity. Harmonizing the metabolic syndrome: a joint interim statement of the International Diabetes Federation Task Force on Epidemiology and Prevention; National Heart, Lung, and Blood Institute; American Heart Association; World Heart Federation; International Atherosclerosis Society; and International Association for the Study of Obesity. Circulation 120:1640-1645 (2009).

20. Robins SJ, Lyass A, Zachariah JP, et al. Insulin resistance and the relationship of a dyslipidemia to coronary heart disease: the Framingham Heart Study. Arterioscler Thromb Vasc Biol. 31:1208-1214 (2011).

21. Miller M, Stone NJ, Ballantyne C, et al. American Heart Association Clinical Lipidology, Thrombosis, and Prevention Committee of the Council on Nutrition, Physical Activity, and Metabolism; Council on Arteriosclerosis, Thrombosis and Vascular Biology; Council on Cardiovascular Nursing; Council on the Kidney in Cardiovascular Disease. Triglycerides and cardiovascular disease: a scientific statement from the American Heart Association. Circulation 123:2292-333 (2011).

22. Goldberg RB, Temprosa M, Mele L, et al. Diabetes Prevention Program Research Group. Change in adiponectin explains most of the change in HDL particles induced by lifestyle intervention but not metformin treatment in the Diabetes Prevention Program. Metabolism 65:764-75 (2016).

23. Matsushita Y, Nakagawa T, Yamamoto S, et al. Adiponectin and visceral fat associate with cardiovascular risk factors. Obesity (Silver Spring) 22:287-291 (2014).

24. Cnop M, Havel PJ, Utzschneider KM, et al. Relationship of adiponectin to body fat distribution, insulin sensitivity and plasma lipoproteins: evidence for independent roles of age and sex. Diabetologia 46:459-469 (2003).
25. Pereira RI, Low Wang CC, Wolfe P, et al. Associations of Adiponectin with Adiposity, Insulin Sensitivity, and Diet in Young, Healthy, Mexican Americans and Non-Latino White Adults. Int J Environ Res Public Health 13:ijerph13010054 (2015).

26. Hanley AJ, Bowden D, Wagenknecht LE, et al. Associations of adiponectin with body fat distribution and insulin sensitivity in nondiabetic Hispanics and African-Americans. J Clin Endocrinol Metab 92:2665-2671 (2007).

27. Schneider JG, von Eynatten M, Schiekofer S, et al. Low plasma adiponectin levels are associated with increased hepatic lipase activity in vivo. Diabetes Care 28:2181-2186 (2014).

28. Terazawa-Watanabe M, Tsuboi A, Fukuo K, et al. Association of adiponectin with serum preheparin lipoprotein lipase mass in women independent of fat mass and distribution, insulin resistance, and inflammation. Metab Syndr Relat Disord 12:416421 (2014).

29. Tsubakio-Yamamoto K, Matsuura F, Koseki M, et al. Adiponectin prevents atherosclerosis by increasing cholesterol efflux from macrophages. Biochem Biophys Res Commun 375:390-394 (2008).

30. Marsche G, Zelzer S, Meinitzer A, et al. Adiponectin Predicts High-Density Lipoprotein Cholesterol Efflux Capacity in Adults Irrespective of Body Mass Index and Fat Distribution. J Clin Endocrinol Metab 102:4117-4123 (2017).

31. Haneklaus M, O'Neill LA. NLRP3 at the interface of metabolism and inflammation. Immunol Rev 265:53-62 (2015).

32. Kishida K, Funahashi T, Shimomura I. Adiponectin as a routine clinical biomarker. Best Pract Res Clin Endocrinol Metab 28:119130 (2014).

33. Bonora E, Targher G, Alberiche M, et al. Homeostasis model assessment closely mirrors the glucose clamp technique in the assessment of insulin sensitivity: studies in subjects with various degrees of glucose tolerance and insulin sensitivity. Diabetes Care 23:57-63 (2000). 